\title{
Computer Supported Control Education from a Linköping Perspective
}

\author{
Svante Gunnarsson and Mille Millnert \\ Department of Electrical Engineering \\ Linköping University, S-581 83 Linköping, Sweden \\ www: http://www.control.isy.liu.se \\ email: svante@isy.liu.se, mille@isy.liu.se
}

1997-09-16

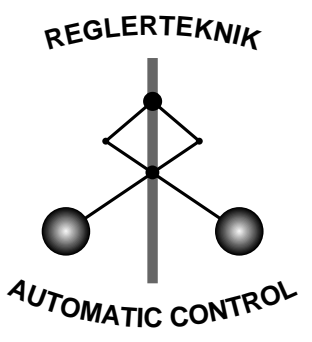

\section{LINKÖPING}

Presented at The 4th IFAC Symposium on Advances in Control Education. Technical reports from the Automatic Control group in Linköping are available by anonymous ftp at the address 130.236.20.24 (ftp.control.isy.liu.se/pub/Reports/). This report is contained in the compressed postscript file 1972.ps.z. 


\title{
COMPUTER SUPPORTED CONTROL EDUCATION FROM A LINKÖPING PERSPECTIVE
}

\author{
S.Gunnarsson and M. Millnert \\ Division of Automatic Control, Department of Electrical Engineering, Linköping \\ University, S-58183 Linköping, Sweden
}

\begin{abstract}
The development of computer supported control education at Linköping University is presented. A review of the different phases of development of computer support is given. The experiences from the introduction of computer supported exams are discussed.
\end{abstract}

Keywords. Control education, Computer aided control system design, Computer Simulation

\section{INTRODUCTION}

The Division of Automatic Control, which belongs to the Department of Electrical Engineering, at Linköping University gives undergraduate courses in the modeling, control and signal processing areas. It has for a long time been an ambition of the group to continuously develop these courses and to adapt them to the new circumstances that are caused by the rapid development of hardware and software suitable for education purposes. This paper gives an overview of how the use of computer support has developed during the last decade, with an emphasis on the last three years development. During these last three years the amount of computer support in the problem solving sessions has increased substantially and computer supported exams have been introduced. The focus in the paper is more on how the topics are taught rather than what the contents of the different courses are.

\section{BACKGROUND}

The Division of Automatic Control gives courses in Automatic Control, Control Theory, Modeling and Simulation, Digital Control and Digital Signal Processing. Since the courses are given for five different engineering programs, some of the courses are given in slightly different versions for different programs. The format of the different courses are however rather similar and the activities in a course can roughly be separated in the following five parts:

- Lectures

- Problem solving sessions

- Laboratory sessions

- Student work
- Exam

The lectures, typically 12 times 2 hours, are normally given by professors or associate professors, while the problem solving sessions, typically 12 times 2 hours, are held by PhD students. Both the lectures and the problem solving sessions are voluntary, but the attendance is normally rather high. The laboratory sessions are compulsory, and a course typically includes 3 lab sessions, where each lab session lasts 4 hours. The point "Student work" represents the time and effort spent by the students to prepare for lectures, problem solving sessions, lab sessions and the exam. Finally, the exam, which normally lasts for 4 hours, has traditionally been of "pen and paper" type.

\section{PHASES OF DEVELOPMENT}

Using the different course components defined above we shall now review the different phases of development of computer support that can be distinguished during the last one and a half decade.

\section{The mainframe phase}

In this first phase the computer support was introduced in one (or several) of the lab sessions. See Figure 1. Using graphical terminals attached to a mainframe computer different aspects of control were studied. The software used included both specially designed software written in FORTRAN, but also some commercial software like Simnon and Synpac, developed at Lund Institute of Technology. Using these tools it was possible carry out simulations and display the results graphically, draw Bode diagrams, etc. This meant a lot for the intuitive 


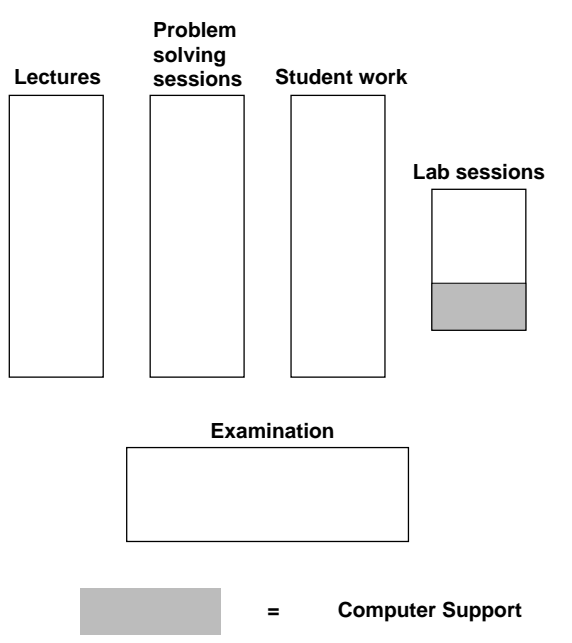

Fig. 1. The mainframe phase

understanding of the subject in terms of e.g. the relationships between open and closed loop Bode diagrams, the relationship between time and frequency domain responses, etc. Due to the limited resources in terms of graphical terminals the computer lab was however only available for the student during the scheduled lab session, which meant that the student spent less than five percent of the time using computer support.

\section{The PC phase}

The next phase was caused by the advent of the $\mathrm{PC}$ and the software PC-MATLAB. This phase was entered during the second half of the eighties and the development was driven by two important factor. First, due to the flexibility of the software more aspects of the subject could now be studied. All relevant signals and diagrams could be computed and plotted very easily. Second, due to the decrease in price for a reasonably powerful computer with graphical capabilities more work places could be arranged. Practically this meant that two labs with fifteen PC:s could now be arranged at the department. This lead to the introduction of computer aided problem solving sessions. See Figure 2. One idea behind this step was to keep the group and the teaching assistant together and simply move the problem session to a computer lab. Specially designed instructions manuals were developed for the computer aided problem solving sessions, and these manuals contained introductions to the software combined with a description of how the different topics in a course could be illustrated using the computer. The main improvements obtained when entering this phase was that more aspects of the subject could be illustrated, and that more time could be spent studying the subject using the computer.

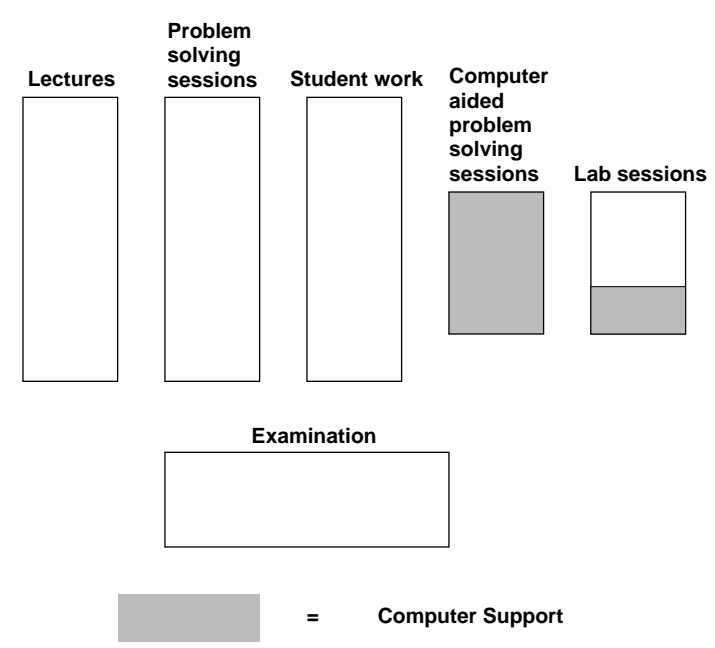

Fig. 2. The PC phase

Another consequence of the arrival of the PC was that real time control of laboratory processes could now more easily be implemented. It therefore became natural to include computer support also in these type of lab sessions.

The workstation phase

Because of a steady increase of computer support in several courses given by the Department of Electrical Engineering it was found that workstations were to be prefered. The labs equipped with PC:s were gradually replaced by workstations, and presently the department has four labs with fifteen SUN workstations each.

With this improvement in computer resources it became realistic to consider exams carried out using the computer. This is a very important step, since the properties of the exam have a big effect on how the students study the subject. It does not only affect the exam itself, but also the preparation before the exam. Computer supported examination was first implemented in the course in Digital Signal Processing during the second half of 1994, and has been used since then.

At the same time the distinction between computer supported and traditional problem solving sessions was removed. The course just contains a number of problem solving sessions, where some of the sessions are carried out in a computer lab. See Figure 3. Due to the increased number of computers it was possible to let the students use the computer labs more than at the scheduled occasions. This is necessary in order to give the student possibilities to prepare for the exam. Gradually also the number of students having their own computer has increased. These two factors have contributed to an 


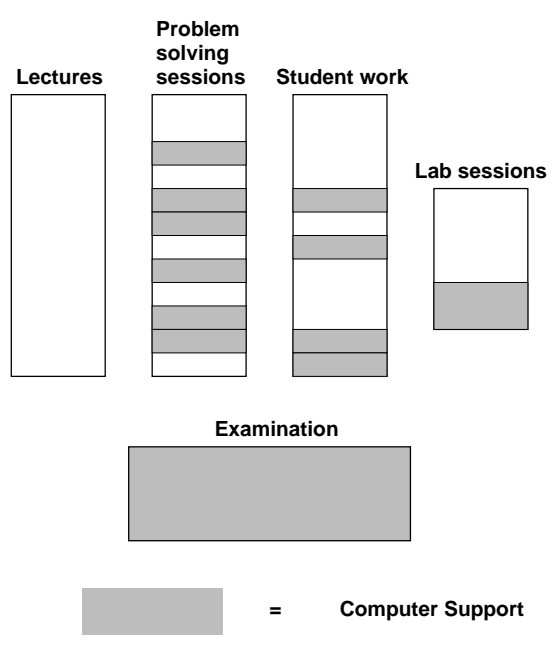

Fig. 3. The workstation phase

increase in the time spent by the student using the computer in the preparation for problem solving sessions, lab sessions and the exam.

\section{The laptop phase}

Even though the computer facilities are good with several labs equipped with workstations an even more flexible environment is, for several reasons, desirable. With an increasing number of computer aided problem solving sessions the scheduling problems becomes difficult. In order to make the conditions more flexible, and to make the students independent of any special location for their work a situation with a personal laptop computer for each student would be of interest. This would enable the student to solve problems and prepare themselves at home as well at the university. See Figure 4. In

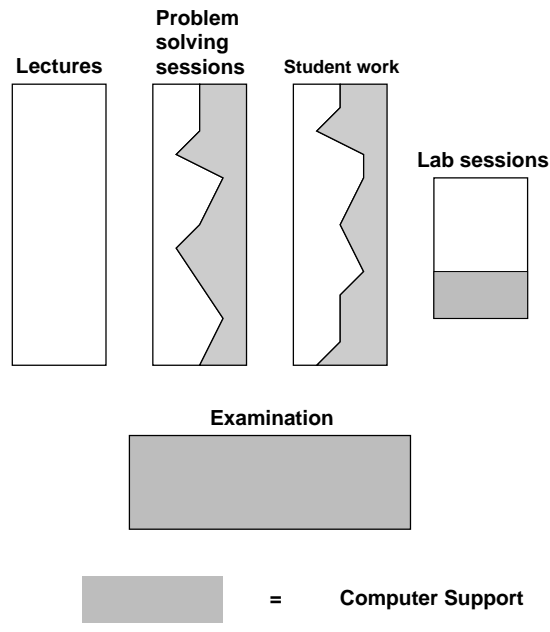

Fig. 4. The laptop phase

order to test this idea an experiment with laptop com- puters has been carried out during the first half of 1996 . A number of groups from different engineering programs taking different courses have been given the possibility to borrow a laptop computer during one study period, which lasts for approximately two months.

\section{SOFTWARE}

For different reasons the Division of Automatic Control has chosen to use MATLAB as the common software tool in the different courses. One reason is that it has been considered as an advantage to make the students familiar with an example of commercial software in the control and signal processing area. Second, by using only commercially available software the amount of in-house produced software is minimized. This is considered to be an advantage in terms of maintenance, etc. Standard MATLAB is used together with Control System Toolbox, Signal Processing Toolbox, System Identification Toolbox and Simulink. In the basic course in Automatic Control only a small library of in-house written functions is used.

Linköping University has a license agreement, which makes MATLAB and toolboxes available for all students and teachers. It is also possible for the students to install the software on their own computers.

\section{EXAMINATION}

A major step in the use of computer supported education was taken by the introduction of the computer aided exam. This was first introduced in the course in Digital Signal Processing given during the second half of 1994. Since the character of the exam has a big impact on the activities of the student the introduction of computer aided exams implies a rather fundamental change of the studies. The format of the exam is however so far the same as before, and the big difference is that the students are sitting at a workstation while the exam is carried out. The student decides if a problem is easiest solved by using the computer or if calculations by hand are more suitable. Manuals for the different software packages are available.

With the computer available at the exam it is now possible to give problems of a type that is unrealistic to solve without the computer. We shall give two examples of such problems, where one example is from Digital Signal Processing and the second is from Control Theory.

Example: The file data1.mat contains a signal which has been sampled with sampling frequency $100 \mathrm{~Hz}$. The 
signal contains three sinusoids hidden in noise. Find the frequencies of the three sinusoids.

Example: A linearized state space model of an inverted pendulum is defined by the matrices $A, B$ and $C$ can be found on the file data2. mat Assume that all states can be measured and design a state feedback such that the requirements given below are fulfilled.

Problems of this type are more realistic than problems that can be given when only a pocket calculator is available. In general one finds that problems where the emphasis is on routine calculations are less meaningful to give, while problems that are evaluating the understanding of the subject on a higher level now are possible. Looking at traditional exams it is easy to find examples that are not meaningful to give any more, having the computer available.

\section{EVALUATION}

The new course concept including computer supported exams has so far been implemented in three different courses with participants from four different engineering programs. The overall experiences are very good, and the new ideas have been accepted by the students as natural and useful steps towards better understanding of the subjects. It is possible to distinguish three major positive effects of the new course concepts, and these are:

- Experience of modern software

- Increased student activity

- Higher knowledge level

\section{Experience of modern software}

The knowledge of modern software in the automatic control and signal processing areas is important for an engineer. It is therefore motivated to give the student a thorough knowledge of how problems in these areas can be handled using computers and modern software.

\section{Increased student activity}

In traditional problem solving sessions there is always a risk that the students become passive and simply copy the solutions presented by the teacher. Using computers this situation is eliminated almost completely, and the student activity is normally very high.
Higher knowledge level

As discussed above it is now possible to formulate and solve problems of more complex character. Instead of formulating problems that mainly test the ability to carry out certain calculations it is now possible to formulate problems that include both analysis and design aspects.

\section{PRACTICAL CONSIDERATIONS}

It is impossible to avoid that the new course format will have some practical consequences, like for example:

- Subject knowledge vs tool knowledge.

- Volume limitations.

\section{Subject vs tools}

The use of computers can be seen as a natural development step, where the pocket calculator is replaced by a computer. Due to the larger complexity of the tool it is obvious that it requires more training to learn how to use the new tool efficiently. One way to enable a sufficient experience of the software tool is to have sufficiently many computer aided problem solving sessions. A second way is to give the student good access to the computer facilities and to the software. It is however important to ensure that the studies of the tool does not replace the studies of the subject itself.

\section{Volume limitations}

One limitation that prevents the implementation of the new course format in all courses is the number of computers available for the exam. In order to arrange a computer supported exam in some of the basic Automatic Control courses it would be necessary to have almost 200 computers available. This is not possible at the moment, but hopefully this can be arranged in the future by, for example, cooperation between the departments.

\section{CONCLUSIONS}

The development of computer aided control education, causes by the rapid development of both hardware and software, has been discussed. In particular we have focused on the introduction of computer supported problem solving sessions and exams. 